\title{
IJIMI
}

International Journal of Machine Intelligence

ISSN: 0975-2927 \& E-ISSN: 0975-9166, Volume 3, Issue 2, 2011, pp-58-61

Available online at http://www.bioinfo.in/contents.php?id=31

\section{WIRELESS FRAMEWORK FOR MONITORING AND CONTROLLING AGRICULTURAL ACTIONS}

\section{GOLLAGI S.G..$^{*}$ AND RAJPUROHIT V.S. ${ }^{2}$}

1Department of CSE, Hirasugar Institute of Technology, Nidasoshi-591 236, Karnataka, India

2Department of CSE, Gogate Institute of Technology, Belgaum-590008, Karnataka, India

*Corresponding author. Email: shantesh1973@rediffmail.com

Received: August 10, 2011; Accepted: August 16, 2011

\begin{abstract}
To monitor \& control the remotely situated Electro-Mechanical system or system parameters' we propose novel wireless framework using cell phones's SMS facilities. Our system enables the farmer to get the intimation about status both on demand as well as automatically in critical situations viz. water level in the tank or well, voltage and current level, water level reached in the field while pouring water to the crop, pressure, Temperatures etc. in the form of feedback SMS and control the operations of the system accordingly. We also made an attempt to keep the log of the status of various parameters in a PC for future reference. The system has been tested on-field for monitoring and controlling Pump-Set actions and pouring the water to crops based on soil condition. We found that results are very satisfactory and encouraging given the simplicity and cost effectiveness of the framework.
\end{abstract}

Keywords: Trans-receiver, Moisture, Motor, Microcontroller, Driver relay, Sensor, Modem, Simulator

\section{INTRODUCTION}

General objective of our frame work is to control any electro-mechanical system through cell phone [1]. And also monitor \& keep log of status of required system's parameters automatically. Basically, in fields the farmers use 3-phase motors, but to due to scarcity of power, loading shadings are common and poopower power fluctuations are quite often. Under such circumstances the farmers must go to the motor location every time to start/stop it. If the well /tank gets dry then motor may run dry without water which may in turn damage the motor system. Further, water utilization would be poor. To overcome these and many others, frame work has been proposed using state of the art methodology. We applied our gadget to agriculture applications. However, it can also be adapted to many other industrial applications as well.

To the best of our knowledge:

a) Existing system comes with an auto starter mainly used for automatic switch ON, but that cannot be used for switch OFF.

b) There is no acknowledgement for any status information of the system which would leads to the system damage under critical conditions [2].

c) Existing system will not have a support for any field sensors to monitor/control the system and make optimal utilization of water and other resource.

d) d) Existing system's cost is very high considering its functionalities. The Analysis of impact of the environment and network parameters on the estimation distortion of the soil moisture is found in [4]

\section{PROPOSED APPROACH}

The proposed work focus on a cellular monitoring / controlling and status logging. This gadget can be used to control the remotely located system or particular system's parameters through cell phone's SMS facility. The Architecture of the frame work is shown in Fig. (1).

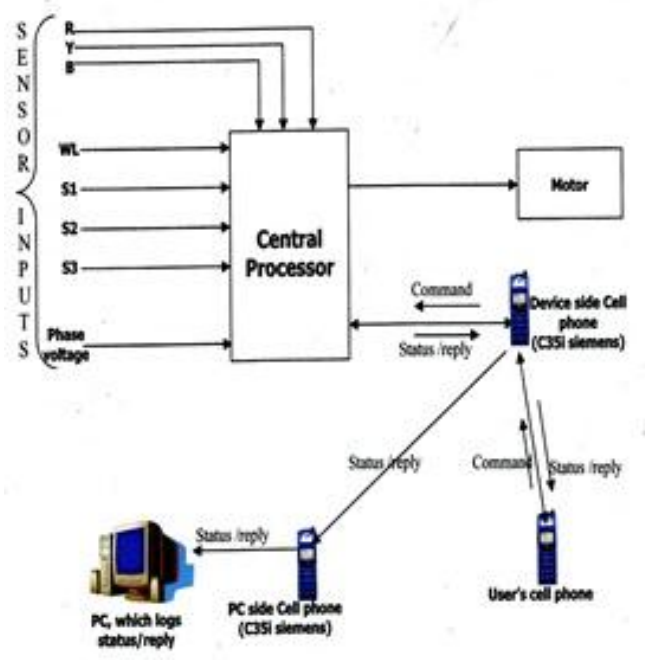

Fig. 1-General architecture of the proposed Frame work. Also, it is possible to get the intimation of the status on 
request by the farmers or automatically in critical conditions. SMS (Text message, Viz. STATUS, START $M$, STOP $M$ etc.) act as a command. Since these commands and phone number of the device side cell phone is known to user only; it gives the security/privacy to the system. Proposed system has many benefits: Support for monitoring and/or controlling of remote device at minimum cost; Provides feedback to user about status log of the system, which will be helpful in where there is a requirement of past data; Optimal utilization of resource (e.g. Water and Electricity); It's also secure one.

\section{METHODOLOGY}

System continuously reads the input data from various sensors on field and regularly perform system status check and generate required signals, act accordingly. Also reads the commands sent by user through SMS and take appropriate actions and sends feedback to user. Sample flowchart is shown in fig.(2). below.

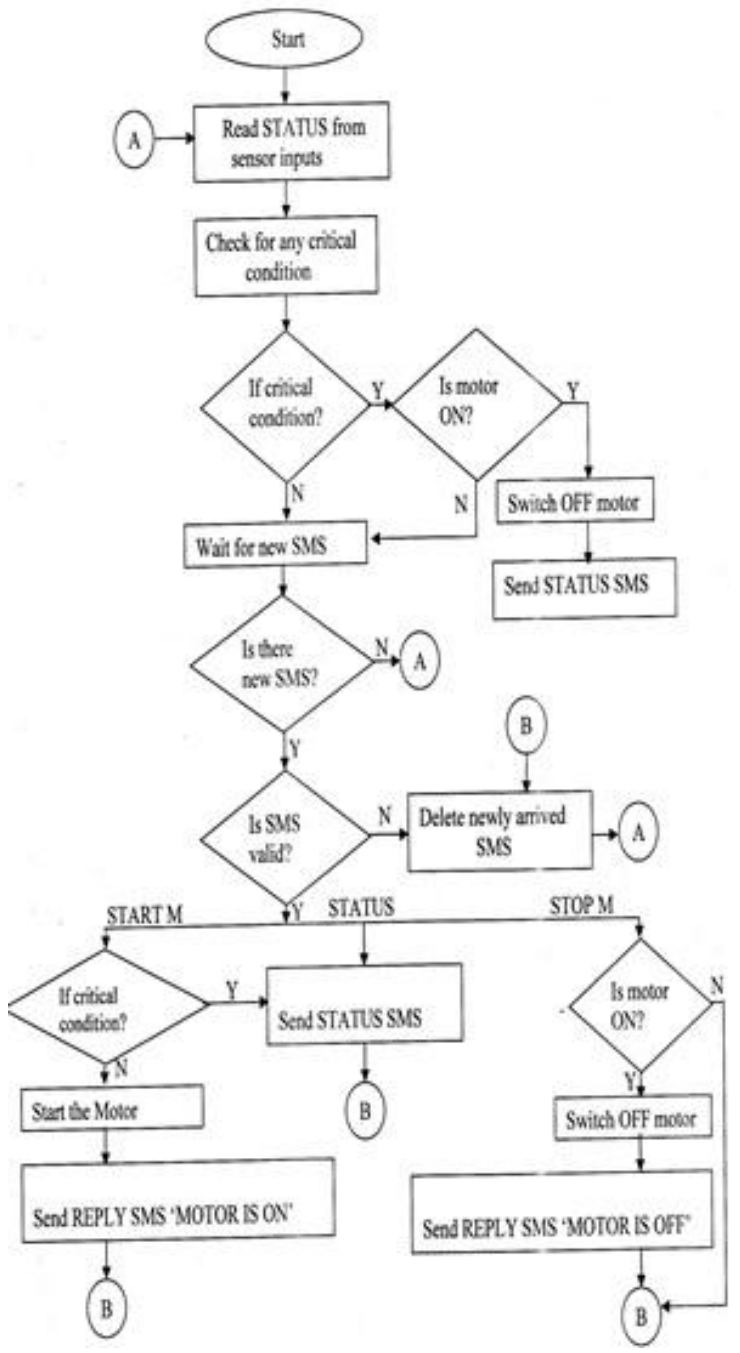

Fig. 2-Sample Flowchart for monitoring and Controlling. To operate the system user must have knowledge of operating the cell phone, especially SMS facilities. To know phases (RYB) information, the condition of sensors (field sensors, Water level sensors etc.) and voltage level, he/she sends message STATUS to destination cell that is connected to gadget. Based on request made our gadget automatically sends reply message like: 1) PHASE: RYB, V: 230, WL: H, SENSORS: 12x. In this Message RYB indicates all 3-phases are present, $H$ indicates high water level at water source and ' $12 x$ ' indicates water is reached up to sensors $1 \& 2$ and sensor 3 is dry. 2) PHASE: RYx, V: 198, WL: L, SENSORS: 12x Here: 'RYX' indicates only R\&Y phases are present and $B$ phase is absent, ' $L$ ' indication for low level water at source and ' $12 x$ ' indicates water reached up to sensor 1 $\& 2$, sensor 3 is dry. Other Message includes START $M$, STOP $M$ to turn ON and turn OFF system (Motor) respectively. Under critical conditions like absence of any phase, water level is low etc. then motor is automatically switched OFF and STATUS message is send to the user. By this user can come to know that motor is stopped and causes for that.

\section{SYSTEM REQUIREMENTS Hardware Modules:}

Major Hardware module includes: RYB Phase checker, Moisture detection, Motor Driver, Voltage reading module etc. Some of the important modules are presented below.

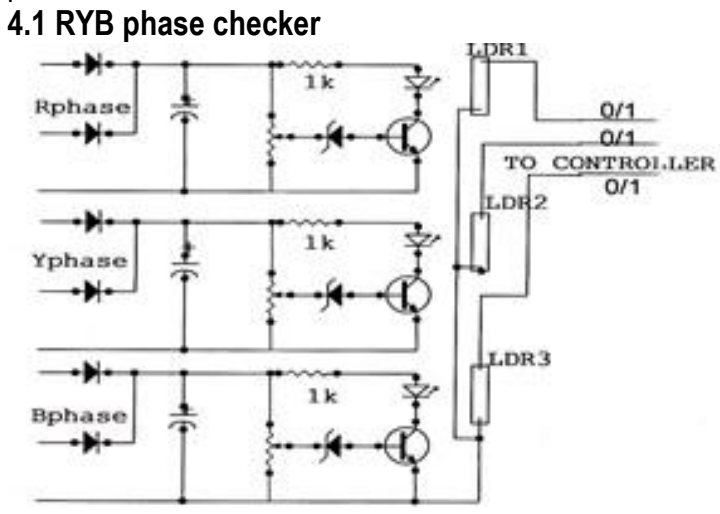

Fig. 3-Circuit Diagram for RYB Checker.

This module monitor RYB phase for their absence/presence and report the same to Microcontroller. Major Components used: Step down transformer, LEDs, LDR-Light Dependent Resistor (photo sensor), and Diodes etc. Refer fig.(3) for complete circuit diagram.

INPUT: Analog 3-phase Voltage.

OUTPUT: Digital signal (0/1) for each phase RYB.

\subsection{Moister Detector}

This module checks the Moisture level. We employed copper conductor as moisture sensors. These conductors will pass current through it if moisture is present and disconnect the supply when soil is dry. It means sensor will play the role of short circuit or open circuit as per the soil condition. Soil moisture sensors measure the water content in soil

The circuit diagram for mapping sensor output to desired input for microcontroller is shown in Fig.(4).

Graph showing the results of moister sensors is shown in Fig. (6). 


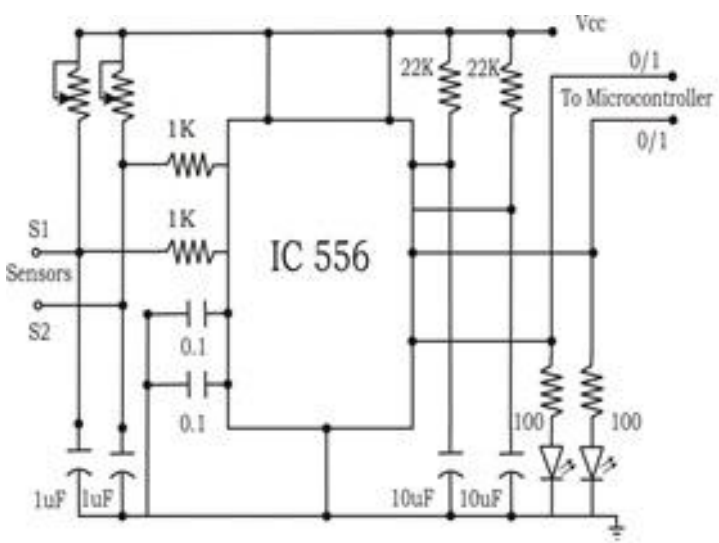

Fig. 4-Circuit diagram for Moister Detection.

Major Components Used: Copper Conductor (sensor), 556IC (Monostable Multivibrator) etc.

INPUT: Soil's moister level (from sensor)

OUTPUT: Digital Signal $(0 / 1)$

\subsection{Motor Driver}

This module simply enables us to switch on/off the relay according to output of the microcontroller, which in turn cause on/off of the motor in the field.

This circuit comprises a relay and transistorized relay driver. When operator wants to switch ON the machine/motor, microcontroller send $\mathrm{ON}$ signal to its output pin and signal on this pin is first given to transistor base and in turn this transistorized driver operates the relay. For detailed circuit diagram refer Fig. (5).

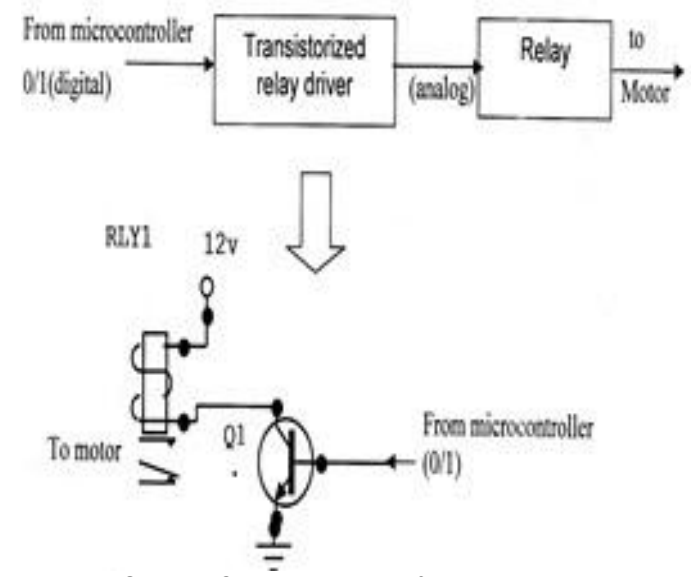

Fig 5-A Simple Circuit diagram for Motor driver.

Major Components Used: Transistorized relay driver, relay etc.

INPUT: Digital signal (0/1) from microcontroller.

OUTPUT: Analog signal to turn ON/OFF device.

\subsection{Status Logging}

This module should be able to read the status of various parameters through the cell and keep log of these for future use. Data read by the mobile through SMS and is forwarded to RS-232 trans-receiver and then to Personal Computer. Personal Computer is programmed in such a way that when new data is read, it is appended to the log file maintained.

Framework is successfully implemented and tested on field agriculture applications using Microsoft XP, Visual Basic 6.0,SMS Encoder/Decoder and Top view Simulator (for programming 8051/8951 microcontroller). However, with suitable modification, Framework would be adopted to many other domains. SMS Encoder/Decoder is a freeware downloaded from www.usbdeveloper.com. The system is fully modularized system and each module is implemented, tested and integrated using software Engineering principles. Other possible area of application includes: Home security, Remote factory Automation, Remote logging system, Remote Voting system etc. In short, with little modifications, our system can be used in many fields where there is requirement of remote controlling, monitoring and/or automatic status logging.

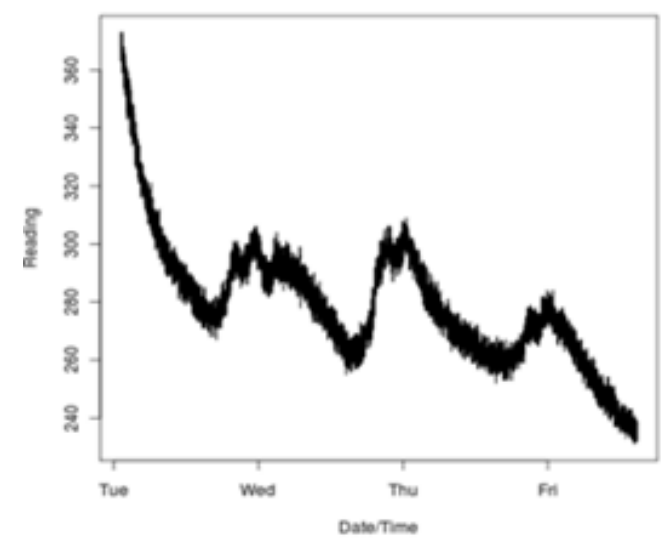

Fig. 6-Graph showing results of Moister Sensor.

\section{EXPERIMENTAL RESULTS}

The accuracy of the proposed system depends on quality of service that SMS service provider supports in the area of application. For experimental purpose, we used two well known cellular service provider: BSNL and Airtel. The Framework was kept under operational for agricultural actions continuously for seven days and SMS drops were recorded for both BSNL and Airtel Networks separately. The performance of the proposed system in terms of SMS drop rate (\%) is shown in fig.(7). The graph in fig.(7) indicates that BSNL Network has performed well when compared to Airtel Network as the SMS drop rate(\%) is significantly less in BSNL system.

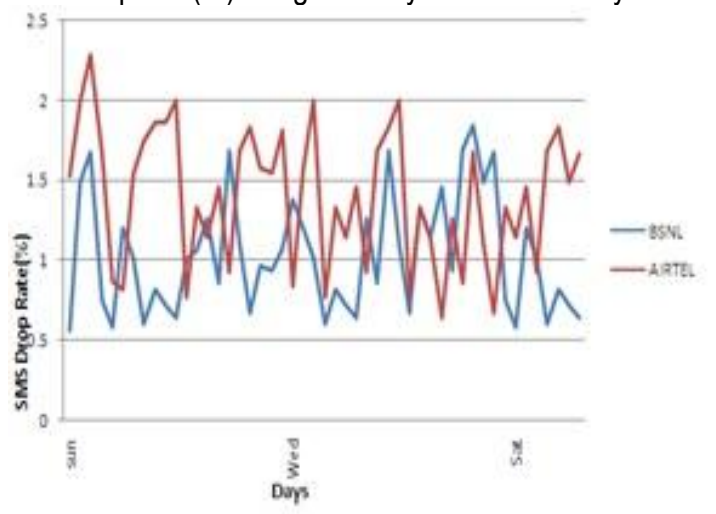

Fig. 7-Graph showing SMS drop rate (in Percentage over week time) 


\section{SAMPLE SCREEN}

The screen showing content of log file at particular moment in time is presented in Fig. (8) below.

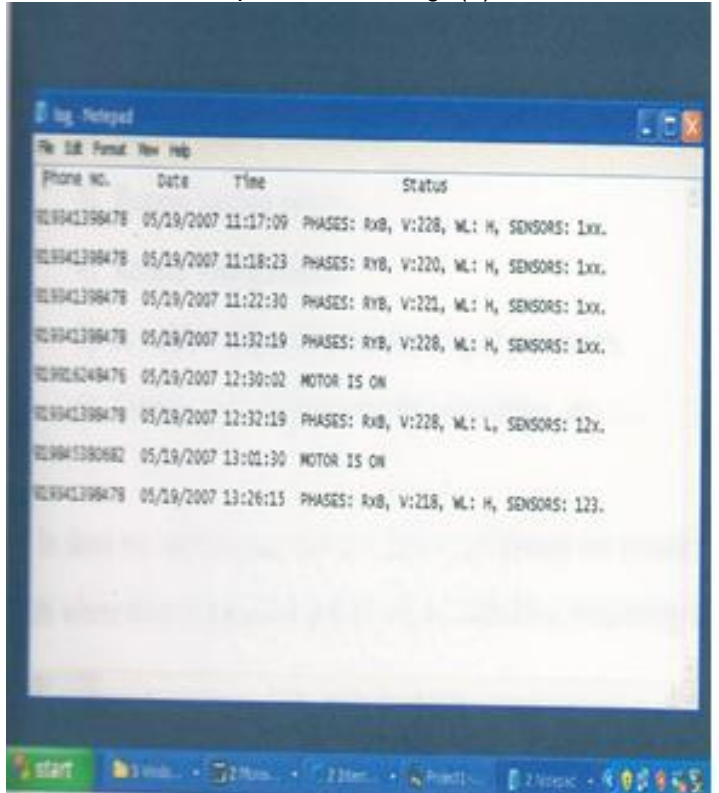

Fig. 8-Sample screen showing status log.

\section{CONCLUSION}

In India, agriculture is the main profession of people and Electricity supply is more irregular and fields are far away. We believe that, gadget will be very much useful for our farmers for monitoring and controlling agricultural activities. At the same time our gadget ensures optimal utilization of resources like Electricity, Water etc. The only drawback associated with our gadget is that necessity of cell network in the area of application.

\section{REFERENCES}

[1] Wiberg P. and Bilstrup U. proc. IEEE Int. Conf. Emerging technologies and Factory automation, 122-133.

[2] Willig A., Matheus K. and Wolisz A. (2005) Proceedings of the IEEE,.93, 6 .

[3] Upper Saddle River, New Jersey: Prentice-Hall "Chapter 6, Water in soils: infiltration and redistribution", ISBN 0-13-099695-5, Physical Hydrology (II ed.)., Inc. 646.

[4] Xin Dong and Mehmet C. Vuran (2010) The 9th IFIP Annual Mediterranean Ad Hoc Networking Workshop (Med-Hoc-Net).

[5] "Electronics for you", Magazine, March-2007.

[6] Mohammad ali Mazidi and Janice Gillespie Mazidi. "The 8051 Microcontroller and Embedded system: Text-book" 